\title{
A simple nonradioactive method for the determination of the binding affinities of antibodies induced by hapten bioconjugates for drugs of abuse
}

\author{
Oscar B. Torres ${ }^{1,2}$ • Joshua F. G. Antoline ${ }^{3,4}$ - Fuying Li ${ }^{3,4,5} \cdot$ Rashmi Jalah $^{1,2}$. \\ Arthur E. Jacobson ${ }^{3,4}$ • Kenner C. Rice ${ }^{3,4} \cdot$ Carl R. Alving ${ }^{1} \cdot$ Gary R. Matyas $^{1}$
}

Received: 25 September 2015 / Revised: 15 November 2015 / Accepted: 25 November 2015 /Published online: 16 December 2015

(C) The Author(s) 2015. This article is published with open access at Springerlink.com

\begin{abstract}
The accurate analytical measurement of binding affinities of polyclonal antibody in sera to heroin, 6acetylmorphine (6-AM), and morphine has been a challenging task. A simple nonradioactive method that uses deuteriumlabeled drug tracers and equilibrium dialysis (ED) combined with ultra performance liquid chromatography/tandem mass spectrometry (UPLC/MS/MS) to measure the apparent dissociation constant $\left(K_{\mathrm{d}}\right)$ of antibodies to 6-AM and morphine is described. The method can readily detect antibodies with $K_{\mathrm{d}}$ in the low nanomolar range. Since heroin is rapidly degraded in sera, esterase inhibitors were included in the assay, greatly reducing heroin hydrolysis. MS/MS detection directly measured the heroin in the assay after overnight $\mathrm{ED}$, thereby allowing the quantitation of \% bound heroin in lieu of $K_{\mathrm{d}}$ as an alternative
\end{abstract}

Electronic supplementary material The online version of this article (doi:10.1007/s00216-015-9223-z) contains supplementary material, which is available to authorized users.

Gary R. Matyas

gmatyas@hivresearch.org

1 Laboratory of Adjuvant and Antigen Research, US Military HIV Research Program, Walter Reed Army Institute of Research, 503 Robert Grant Avenue, Silver Spring, MD 20910, USA

2 U.S. Military HIV Research Program, Henry M. Jackson Foundation for the Advancement of Military Medicine, 6720A Rockledge Drive, Bethesda, MD 20817, USA

3 Drug Design and Synthesis Section, Molecular Targets and Medications Discovery Branch, National Institute on Drug Abuse, National Institutes of Health, Department of Health and Human Services, 9800 Medical Drive, Bethesda, MD 20892, USA

4 National Institute on Alcohol Abuse and Alcoholism, National Institutes of Health, 9800 Medical Drive, Bethesda, MD 20892, USA

5 Present address: WuXi AppTec (Shanghai) Co., Ltd, 288 FuTe Road, Waigaoqiao Free Trade Zone, Shanghai 200131, China measurement to assess heroin binding to polyclonal antibody sera. This is the first report that utilizes a solution-based assay to quantify heroin-antibody binding without being confounded by the presence of 6-AM and morphine and to measure $K_{\mathrm{d}}$ of polyclonal antibody to 6-AM. Hapten surrogates 6-AcMorHap, 6-PrOxyHap, MorHap, DiAmHap, and DiPrOxyHap coupled to tetanus toxoid (TT) were used to generate high affinity antibodies to heroin, 6-AM, and morphine. In comparison to competition ED-UPLC/MS/MS which gave $K_{\mathrm{d}}$ values in the nanomolar range, the commonly used competition enzymelinked immunosorbent assay (ELISA) measured the $50 \%$ inhibition concentration $\left(\mathrm{IC}_{50}\right)$ values in the micromolar range. Despite the differences in $K_{\mathrm{d}}$ and $\mathrm{IC}_{50}$ values, similar trends in affinities of hapten antibodies to heroin, 6-AM, and morphine were observed by both methods. Competition ED-UPLC/MS/ MS revealed that among the five TT-hapten bioconjugates, TT6-AcMorHap and TT-6-PrOxyHap induced antibodies that bound heroin, 6-AM, and morphine. In contrast, TT-MorHap induced antibodies that poorly bound heroin, while TTDiAmHap and TT-DiPrOxyHap induced antibodies either did not bind or poorly bound to heroin, 6-AM, and morphine. This simple and nonradioactive method can be extended to other platforms, such as oxycodone, cocaine, nicotine, and methamphetamine for the selection of the lead hapten design during substance abuse vaccine development.

Keywords Heroin hapten · Competition ELISA · Equilibrium dialysis $\cdot$ UPLC/MS/MS $\cdot$ Apparent dissociation constant $\left(K_{\mathrm{d}}\right) \cdot$ Antibody affinity

\section{Introduction}

Therapeutic vaccines to drugs of abuse obstruct the psychoactive effects of the drugs by inducing antibodies that bind and 
prevent the drugs from traversing the blood-brain barrier [1, 2]. The development of a heroin vaccine presents a particular challenge because heroin rapidly metabolizes in serum to 6acetylmorphine (6-AM) and morphine [3]. For effective sequestration of the drugs, hapten bioconjugate vaccines must induce both high titer and high affinity antibodies not only to heroin, but also to 6-AM and morphine [4, 5]. Vaccines to drugs of abuse have been increasingly explored as an alternative treatment for drug addiction. Vaccines have been efficacious in blunting the physiological effects of heroin and other abused drugs in animals. Several studies have demonstrated that the affinity and titer of the induced antibodies $[1,2]$ and hapten density $[6,7]$ of the hapten-protein conjugates are critical components of vaccine efficacy. There is a general agreement that enzyme-linked immunosorbent assay (ELISA) can readily and reliably quantify antibody titer [8-11]. In contrast, the measurement of hapten antibody affinity to heroin and its metabolites, as well as other substances of abuse, is generally estimated by competition ELISA [12, 13]. Concerns have been raised that competition ELISA does not accurately measure the antibody affinity $[7,14,15]$. Several of these concerns are as follows: (1) In serum, heroin is rapidly deacetylated to 6-AM and morphine by blood esterases (Fig. 1a) [16-20]. The enzymatic degradation of heroin during the assay changes the concentration of the drugs, and therefore, the calculated affinity constant may not be for heroin per se but for mixture of drugs. (2) The accuracy of ELISA is dependent on the hapten density of the coating agents [21]. (3) There is a localized high concentration of the hapten coated on the well, which allows for both arms of the immunoglobulin $\mathrm{G}(\mathrm{IgG})$ to bind to the well resulting in the requirement of high concentrations of competitive inhibitor to prevent antibody binding. (4) Similarly, the affinity of the antibody to the immunizing hapten is most likely higher than its affinity to the competitive inhibitor resulting in the further requirement of high concentrations of the competitive inhibitor. Based on these issues, a new methodology for the accurate measurement of the affinity of antibodies to drugs of abuse needs to be developed.

Equilibrium dialysis (ED) is the standard method for measuring the affinity of proteins to small molecules [22]. However, conventional ED between polyclonal sera and drugs cannot be employed to calculate the apparent dissociation constant $\left(K_{\mathrm{d}}\right)$ because the antibody concentration is unknown. To circumvent this problem, a competition ED utilizing radioactive tracers as competitive inhibitors is often employed (Müller's method) [23]. For the antibodies induced by heroin vaccines, the use of radioactive tracers to study heroinantibody binding presents two main challenges. First, radioactive heroin and 6-AM are not commercially available. Second, the short half-life of heroin and its metabolites in sera is not compatible with the long equilibration time required for ED. We posit that (1) by using an alternative probe and detection system and (2) by identifying assay conditions that prevent the degradation of heroin and its metabolites during ED, binding affinities of heroin, 6-AM, and morphine to polyclonal antibody could be assessed.

Liquid chromatography coupled with mass spectrometry is a valid approach for the detection of drug metabolites in biological fluids and could be used to quantify drugs that are bound to the antibody [24]. We rationalized that
Fig. 1 Heroin metabolites and heroin haptens. Degradation of heroin in humans (a). Heroin haptens with different linker attachment points (b). Haptens were coupled to tetanus toxoid (TT) to yield the TT-hapten bioconjugates a

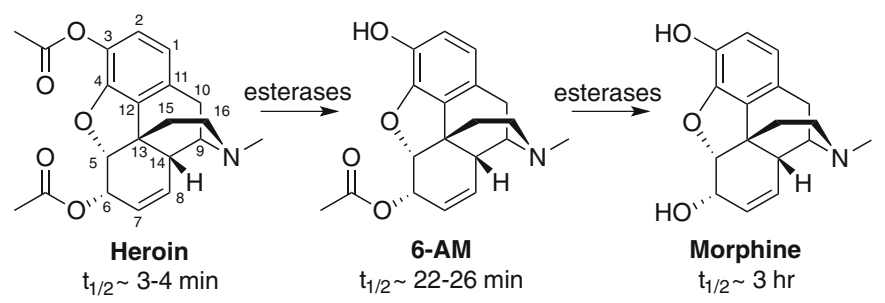

b

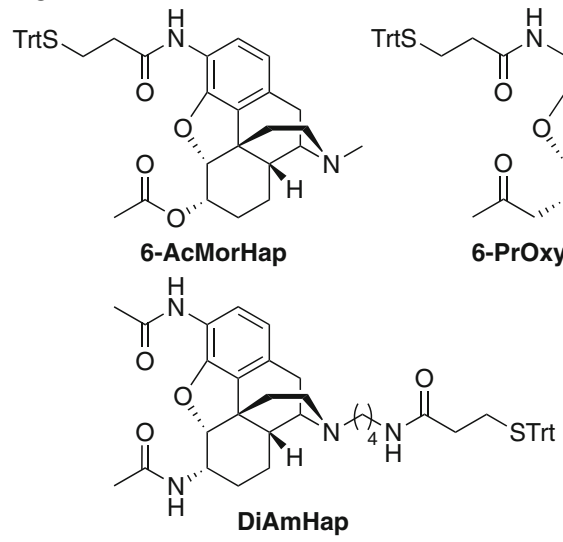

6-PrOxyHap<smiles>CC(=O)Cc1ccc2c3c1O[C@H]1[C@@H](CC(C)=O)CC[C@H](C2)[C@]31CCNC=NC(=O)CC[Sn]</smiles> 
nonradioactive deuterium-labeled drug tracers $\left(\mathrm{D}_{3}\right.$-tracers), such as $\mathrm{D}_{3}$-heroin, $\mathrm{D}_{3}$-6-AM, and $\mathrm{D}_{3}$-morphine, instead of radioactive analogs could be used as tracers in ED. In these $\mathrm{D}_{3}$-tracers, the methyl group of nitrogen is replaced by $\mathrm{CD}_{3}$ (see Electronic supplementary material (ESM) Fig. S1). Since the mass difference between the $\mathrm{D}_{3}$-tracer and corresponding unlabeled drug is significant ( $\Delta$ mass $=3.02 \mathrm{amu})$, mass spectrometry will be able to discriminate these structurally similar molecules. From an analytical standpoint, the obvious advantage of using $\mathrm{D}_{3}$-tracer/liquid chromatography/mass spectrometry as a probe/detection system over radioactive tracer/ scintillation counter and unlabeled drug/enzymatic colorimetric method (ELISA) is that the former can evaluate the integrity of the probe during the assay condition and thereby an unambiguous affinity constant can be determined. We herein report a nonradioactive competition ED coupled with ultra performance liquid chromatography tandem mass spectrometry (UPLC/MS/MS) method that we used to assess the accurate binding affinities of heroin hapten antibodies to 6-AM and morphine. Using this method, (1) we demonstrate that different heroin hapten designs can induce antibodies of varying affinities (Fig. 1b), and (2) we substantiate that the concerns raised about competition ELISA are valid and that the simple methodology of competition ED-UPLC/MS/MS should be used to more accurately measure substance abuse vaccine-induced antibody affinity for the abused substance.

\section{Materials and methods}

Tritylmercaptopropionic acid ( $\geq 98 \%$ ) was acquired from Chem-Impex International (Wood Dale, IL, USA). Chemical reagents and solvents were ACS reagent grade, obtained from Sigma-Aldrich Chem. Co., and were used without further purification. N-hydroxysuccinimide (NHS, $98 \%$ ), acetic anhydride $\left(\mathrm{Ac}_{2} \mathrm{O}, \geq 99 \%\right.$ ), 4-(dimethylamino)pyridine (DMAP, $\geq 99 \%$ ), formic acid for mass spectrometry, tetraisopropyl pyrophosphoramide (iso-OMPA), and bis(4-nitrophenyl) phosphate (BNPP, $99 \%$ ) were purchased from Sigma-Aldrich (Saint Louis, MO, USA). Calibrated solutions $(1 \mathrm{mg} / \mathrm{mL})$ of heroin.HCl. $\mathrm{H}_{2} \mathrm{O}, \mathrm{D}_{3}$-heroin.HCl, 6-AM.HCl, $\mathrm{D}_{3}$-6-AM.HCl, morphine. $\mathrm{H}_{2} \mathrm{O}$, and $\mathrm{D}_{3}$-morphine that were used for $\mathrm{ED}$ were purchased from Lipomed (Cambridge, MA, USA). Calibrated solutions used were Certified Reference Materials. Optima ${ }^{\mathrm{TM}}$ LC/MS grade ammonium formate $\left(\mathrm{NH}_{4} \mathrm{HCOO}\right)$, methanol $(\mathrm{MeOH})$, acetonitrile $(\mathrm{ACN})$, and water $\left(\mathrm{H}_{2} \mathrm{O}\right)$ were purchased from Fischer Scientific (Suwanee, GA, USA). Anti-morphine antibody (ab1060) was purchased from Abcam (Cambridge, MA, USA). Single-use equilibrium dialysis plate with 48 inserts was purchased from Thermo Fisher Scientific (Waltham, MA, USA). An insert (dialysis cassette) contains a sample and a buffer chamber separated by a membrane with $12 \mathrm{~K}$ molecular weight cutoff. Screw neck total recovery vial with polytetrafluoroethylene/silicone septa was purchased from Waters (Cambridge, MA, USA). Dulbecco's phosphate buffered saline (DPBS, $10 \mathrm{mM} \mathrm{Na} \mathrm{HPO}_{4}, 1.8 \mathrm{mM}$ $\mathrm{KH}_{2} \mathrm{PO}_{4}, 2.7 \mathrm{mM} \mathrm{KCl}, 137 \mathrm{mM} \mathrm{NaCl}, \mathrm{pH}$ 7.4) that was used for equilibrium dialysis was purchased from Quality Biological Inc. (Gaithersburg, MD, USA).

\section{Synthesis of 6-AcMorHap}

6-AcMorHap was synthesized in eight steps (Fig. 2). Triftylated hydromorphone (2), 3-desoxydihydromorphinone (3), 1-chloro3-desoxydihydromorphinone (4), and 1-chloro-3-nitrodihydromorphinone (5) were synthesized sequentially from hydromorphone (1) using the procedure described by Li et al. [25]. The detailed synthesis and analytical characterization of 1chloro-3-nitro-dihydromorphine (6), 3-amino-dihydromorphine (7), 3-tritylthiopropanamide-dihydromorphine (9), and 6AcMorHap were described in the ESM. The structure of 6AcMorHap was confirmed by its ${ }^{1} \mathrm{H}$ and ${ }^{13} \mathrm{C}$ nuclear magnetic resonance (NMR) spectra (see ESM Figs. S2 and S3).

\section{Equilibration of $D_{3}$-morphine and morphine}

In a competition $\mathrm{ED}$, the competitive inhibitor is added on one side of the cassette (buffer chamber) and the tracer to the other side (sample chamber). The two chambers are allowed to reach equilibrium prior to measurements. Equilibration time is the incubation period where $\sim 50 \%$ of competitive inhibitor and tracer are located in both the buffer and sample chambers. Morphine (300 $\mu \mathrm{L}, 1333.3 \mathrm{nM}$ in DPBS) and $\mathrm{D}_{3}$-morphine $(100 \mu \mathrm{L}, 5 \mathrm{nM}$ in DPBS) were added into the buffer and sample chambers, respectively. Triplicates were allotted for each time interval: $3,6,12$, and $24 \mathrm{~h}$. The dialysis plate was covered with sealing tape and incubated at $4{ }^{\circ} \mathrm{C} / 300 \mathrm{rpm}$ on a ThermoMixer ${ }^{\circledR} \mathrm{C}$ apparatus (Eppendorf AG, Hamburg, Germany). At a given time point, equal volumes $(90 \mu \mathrm{L})$ were pipetted from both the sample and buffer chambers. The samples were subsequently placed in separate total recovery vials containing $1 \mu \mathrm{L}$ of $10 \%$ aqueous formic acid for UPLC/MS/ MS analysis. The $\%$ drug in the sample and buffer chambers was calculated using the formula:

$\%$ drug $_{\text {sample or bu ffer chamber }}=\frac{[\mathrm{drug}]_{\text {sample or buffer chamber }}}{[\mathrm{drug}]_{\text {sample chamber }}+[\mathrm{drug}]_{\text {bu ffer chamber }}} \times 100$

where $[\mathrm{drug}]_{\text {sample chamber }}$ and $[\mathrm{drug}]_{\text {buffer chamber }}$ are the concentrations of the drug in the sample and buffer chambers, respectively.

\section{Stability of heroin and its metabolites}

For accurate measurement of $K_{\mathrm{d}}$, the drugs must remain stable during the equilibration time. The stability of heroin and its 
Fig. 2 Synthesis of heroin hapten 6-AcMorHap

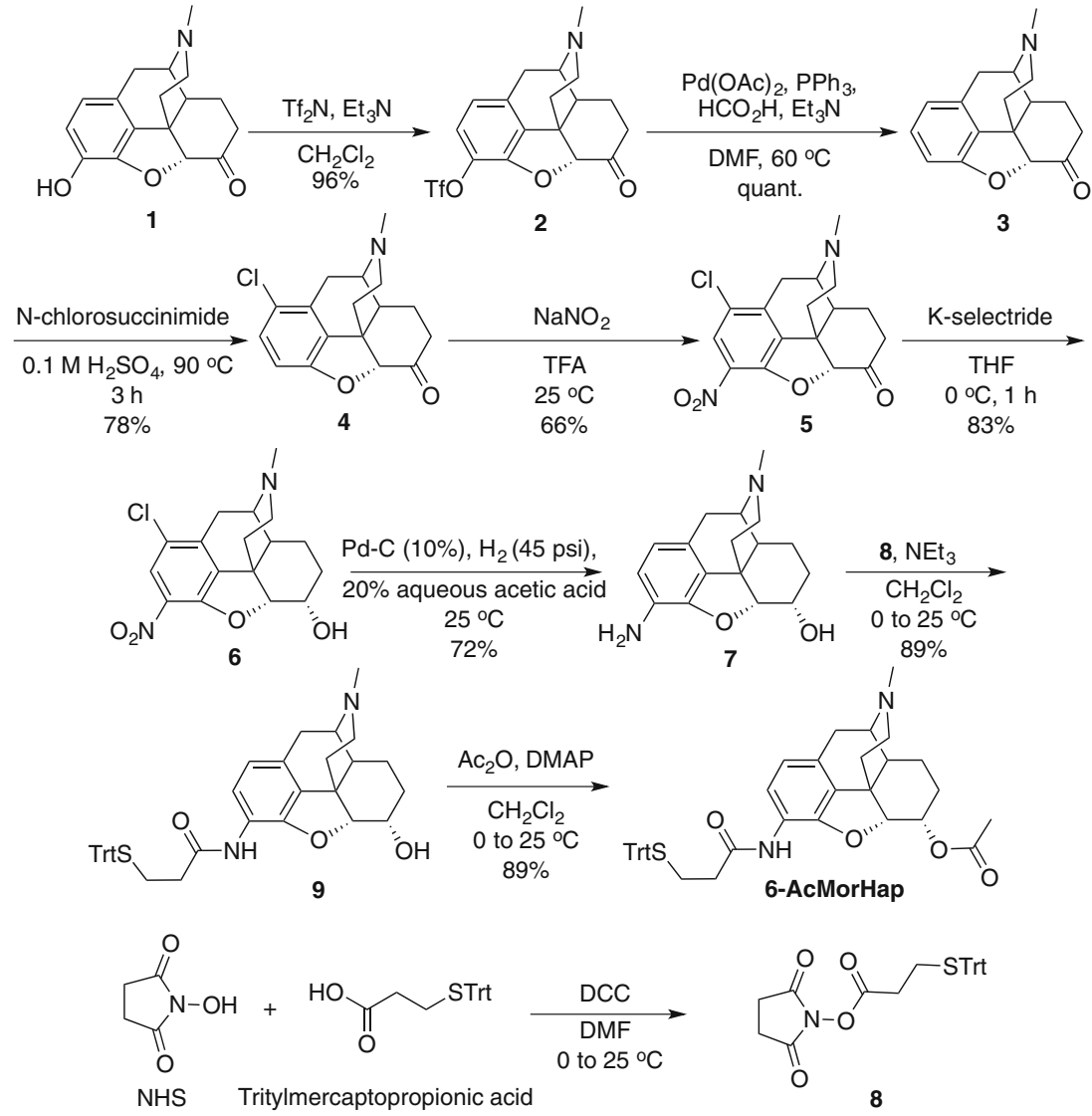

metabolites was assessed at different dilutions of the mouse sera. An aliquot of the drug ( $5 \mathrm{nM}, 400 \mu \mathrm{L}$ in DPBS) was treated with different dilutions $(1: 25,1: 50,1: 100,1: 200$, and $1: 400)$ of mouse sera. The reaction mixture was incubated at $4{ }^{\circ} \mathrm{C}$ and the amount of drug was monitored at a given time interval using UPLC/MS/MS. The \% remaining drug was calculated using the formula:

$\%$ remaining drug $=\frac{[\mathrm{drug}]_{t}}{[\mathrm{drug}]_{\text {initial }}} \times 100$

where $[\mathrm{drug}]_{t}$ is the concentration of the drug at time $t$ and $[\mathrm{drug}]_{\text {initial }}$ is the initial concentration of the drug.

\section{Competition equilibrium dialysis of monoclonal antibody}

Anti-morphine antibody (ab1060) is a mouse monoclonal antibody, supplied as a protein $\mathrm{G}$ purified antibody $(\sim 2 \mathrm{mg} / \mathrm{mL})$. The approximate molecular weight of the $\operatorname{IgG}$ is $155 \mathrm{kDa}$. Based on this information, the antibody concentration of the stock solution is $\sim 12.9 \mu \mathrm{M}$. ab1060 has a reported $K_{\mathrm{d}}$ value of $2 \mathrm{nM}$, which was determined by proprietary ultraviolet-visible (UV-VIS) absorption spectroscopy method that correlated absorbance with the concentration of the ligand-antibody complex [26]. Samples for equilibrium dialysis were prepared by diluting the stock solution in DPBS to yield 2.4, 4.8, and $9.6 \mathrm{nM}$. Inhibition studies were conducted in a single-use equilibrium dialysis plate with inserts following manufacturer's instruction. A $100-\mu \mathrm{L}$ aliquot of ab1060 (2.4, 4.8, and $9.6 \mathrm{nM}$ ) with a fixed amount of $\mathrm{D}_{3}$-morphine (Table 1) was pipetted into the sample chamber, and a $300-\mu \mathrm{L}$ aliquot of the morphine solution in dialysis buffer was added to the

Table 1 Affinity of monoclonal antibody ab1060 to morphine at different concentrations of the antibody and $\mathrm{D}_{3}$-morphine

\begin{tabular}{llll}
\hline Antibody, $\mathrm{nM}^{\mathrm{a}}$ & $\mathrm{D}_{3}$-morphine, $\mathrm{nM}^{\mathrm{a}}$ & $b$ values & \\
\hline 9.6 & 5.0 & $\begin{array}{l}\text { Dissociation constant } \\
\left(K_{\mathrm{d}}, \mathrm{nM}\right)^{\mathrm{c}}\end{array}$ \\
4.8 & 5.0 & $0.94 \pm 0.014$ & $0.11 \pm 0.01$ \\
2.4 & 5.0 & $0.78 \pm 0.012$ & $0.72 \pm 0.05$ \\
2.4 & 2.5 & $0.86 \pm 0.060$ & $0.10 \pm 0.06$ \\
2.4 & 10 & $0.36 \pm 0.001$ & $0.81 \pm 0.07$
\end{tabular}

${ }^{a}$ Initial concentration of binding partners

${ }^{\mathrm{b}}$ Fraction of $\mathrm{D}_{3}$-morphine bound to the monoclonal antibody in the absence of inhibitor

${ }^{\mathrm{c}}$ All $K_{\mathrm{d}}$ values were calculated using Müller's equation and are the mean of triplicate determinations \pm standard deviation

${ }^{\mathrm{d}}$ The affinity that is closest to the reported $K_{\mathrm{d}}$ value of $2 \mathrm{nM}$ 
buffer chamber (1:400, vide infra). Morphine, which is the competitive inhibitor, was prepared at different concentrations. The total volume of the solution in the insert is $400 \mu \mathrm{L}$. The dialysis plate was covered with sealing tape and incubated at $4{ }^{\circ} \mathrm{C} / 300 \mathrm{rpm}$ on a ThermoMixer ${ }^{\circledR} \mathrm{C}$ apparatus. After $24 \mathrm{~h}$, equal volumes $(90 \mu \mathrm{L})$ were pipetted from both the sample and buffer chambers and placed in separate total recovery vials containing $1 \mu \mathrm{L}$ of $10 \%$ aqueous formic acid for UPLC/MS/MS analysis.

\section{Competition equilibrium dialysis of anti-hapten sera}

The preparation of anti-hapten sera and the strategy for conventional and competition ED were described in the ESM. Week 0 and week 9 sera were considered as negative and anti-hapten sera, respectively. Anti-hapten sera solutions were prepared by diluting the sera in DPBS $(1: 400,1: 800$, or 1:600). Dialysis buffer was prepared by diluting the corresponding negative sera in DPBS $(1: 400,1: 800$, or 1:600). Competitive inhibitors with different initial concentrations were prepared in the dialysis buffer. For the test samples, anti-hapten sera/ $\mathrm{D}_{3}$-tracer was run against the negative sera/ inhibitors at the same sera dilution. A $100-\mu \mathrm{L}$ aliquot of antihapten sera containing $5 \mathrm{nM} \mathrm{D}_{3}$-tracer was pipetted into the sample chamber, and a $300-\mu \mathrm{L}$ aliquot of the competitive inhibitor solution was added to the buffer chamber. For negative controls, negative sera/ $\mathrm{D}_{3}$-tracer was run against the negative sera at the same sera dilution. A $100-\mu \mathrm{L}$ aliquot of negative sera containing $5 \mathrm{nM} \mathrm{D}_{3}$-tracer in dialysis buffer was pipetted into the sample chamber, and a $300-\mu \mathrm{L}$ aliquot of the dialysis buffer was added to the buffer chamber. Equilibrium dialysis and preparation of samples for UPLC/MS/MS was performed as described above. In the absence of hapten antibodies (i.e., negative sera), there is no selective partitioning of the $\mathrm{D}_{3}$-tracer in the sample chamber as all negative controls have $0 \%$ bound $\mathrm{D}_{3}$-tracer. After equilibrium, the total concentration of the $\mathrm{D}_{3}$-tracer $\left(\left[T_{\mathrm{t}}\right]\right)$ for both test samples and negative controls was $\sim 1.25 \mathrm{nM}$.

\section{Determination of $b$ values for 6-AM and morphine}

Parameter $b$ is the fraction of bound $\mathrm{D}_{3}$-tracer in the absence of competitive inhibitors. Anti-hapten sera/ $\mathrm{D}_{3}$-tracer was run against the negative sera at the same sera dilution. Briefly, a $100-\mu \mathrm{L}$ aliquot of anti-hapten sera containing $5 \mathrm{nM} \mathrm{D}_{3}$-tracer was pipetted into the sample chamber and dialyzed against $300 \mu \mathrm{L}$ of the appropriate dialysis buffer $(1: 25,1: 50,1: 100,1: 200,1: 400,1: 800,1: 1600)$. Equilibrium dialysis and preparation of samples for UPLC/MS/MS was performed as described above. The calculation of $b$ values is discussed (vide infra) as part of the $K_{\mathrm{d}}$ calculation (see ESM Tables S1-S3).

\section{Determination of \% bound heroin}

Since the hydrolysis of heroin in diluted sera was extensive, the assay was performed in the presence of esterase inhibitors. All sera were diluted in DPBS (1:400) and pretreated with esterase inhibitors (iso-OMPA, $100 \mu \mathrm{M}$ and BNPP, $100 \mu \mathrm{M}$ ) for $1 \mathrm{~h}$ at $4{ }^{\circ} \mathrm{C}$. Briefly, a $100-\mu \mathrm{L}$ aliquot of pretreated dilute sera with $5 \mathrm{nM}$ heroin was pipetted into the sample chamber and dialyzed against $300 \mu \mathrm{L}$ of the dialysis buffer (1:400). Equilibrium dialysis and preparation of samples for UPLC/ MS/MS was performed as described above. The \% bound heroin, which is the \% heroin bound to the antibody in the presence of esterase inhibitors, was calculated using the equation:

$\%$ bound heroin $=\frac{[\text { heroin }]_{\text {bound }}}{[\text { heroin }]_{\text {total }}}=\frac{[\text { heroin }]_{\text {sample chamber }}-[\text { heroin }]_{\text {buffer chamber }}}{[\text { heroin }]_{\text {sample chamber }}} \times 100$

where $[\text { heroin }]_{\text {sample chamber }}$ and $[\text { heroin }]_{\text {buffer chamber }}$ are the concentrations of heroin in the sample and buffer chambers, respectively.

\section{UPLC/MS/MS}

The UPLC conditions and mass spectrometry parameters were derived from Gottas et al. with some modifications [27]. The amount of drugs in the sample and buffer chambers was quantified using a Waters Acquity UPLC/TQD system equipped with an Acquity HSS T3 column $(2.1 \times 100 \mathrm{~mm}$, $1.8 \mu \mathrm{m}$ particle size) maintained at $65{ }^{\circ} \mathrm{C}$. Samples were injected using full loop injection mode $(10 \mu \mathrm{L})$ and ran against a $10-\mathrm{mM} \mathrm{NH}_{4} \mathrm{HCOO} \mathrm{pH} 3.1 / \mathrm{MeOH}$ gradient (flow rate= $0.5 \mathrm{~mL} / \mathrm{min}$ ). The gradient profile is shown in ESM Table $\mathrm{S} 4$. The total cycle time was 8 min to ensure column equilibration prior to the next sample. In addition, a weak wash $\left(600 \mu \mathrm{L}, 10 \% \mathrm{MeOH}\right.$ in $\left.\mathrm{H}_{2} \mathrm{O}\right)$ and a strong wash $(200 \mu \mathrm{L}$, $90 \% \mathrm{ACN}$ in $\mathrm{H}_{2} \mathrm{O}$ ) were performed before each sample to prevent carryover.

Positive ionization was performed in multiple reaction monitoring (MRM) mode. The electrospray and source settings were as follows: $0.7 \mathrm{kV}$ (capillary voltage), $120{ }^{\circ} \mathrm{C}$ (source temperature), $500{ }^{\circ} \mathrm{C}$ (desolvation temperature), $900 \mathrm{~L} / \mathrm{h}$ (desolvation gas flow, $\mathrm{N}_{2}$ ), and $60 \mathrm{~L} / \mathrm{h}$ (cone gas flow, $\mathrm{N}_{2}$ ). The collision gas (Ar) flow in the collision cell was maintained at $0.4 \mathrm{~mL} / \mathrm{min}$. The unlabeled drug and $\mathrm{D}_{3}$-tracer were differentiated based on their mass spectra (see ESM, Figs. S5S10). Drugs were identified by comparing the retention times of the respective MRM transitions with the corresponding standards. Data were processed in the QuanLynx ${ }^{\mathrm{TM}}$ software and the drug concentrations in the sample and buffer chambers were quantified using peak area. 


\section{Calculation of apparent dissociation constant $\left(K_{d}\right)$}

The $K_{\mathrm{d}}$ value can be calculated using Müller's equation [23, 28]:

$K_{\mathrm{d}}=\left(\left[I_{50}\right]-\left[T_{\mathrm{t}}\right]\right)\left(1-1.5 b+0.5 b^{2}\right)$

$\left[I_{50}\right]$, which is the molar concentration of the competitive inhibitor required for $50 \%$ inhibition, was derived through interpolation on the \% inhibition vs $[I]$ curve. $\left[T_{\mathrm{t}}\right]$ is the total molar concentration of the $\mathrm{D}_{3}$-tracer after equilibrium. The fraction of bound $\mathrm{D}_{3}$-tracer $(b)$ in the absence of competitive inhibitor, $I_{0}$, was calculated using the equation:

$b=\frac{\left[\mathrm{D}_{3}-\text { tracer }\right]_{\text {bound, } I_{0}}}{\left[\mathrm{D}_{3}-\text { tracer }\right]_{\text {total }, I_{0}}}=\frac{\left[\mathrm{D}_{3}-\text { tracer }\right]_{\text {sample chamber }}-\left[\mathrm{D}_{3} \text {-tracer }\right]_{\text {buffer chamber }}}{\left[\mathrm{D}_{3} \text {-tracer }\right]_{\text {sample chamber }}}$

where $\left[\mathrm{D}_{3} \text {-tracer }\right]_{\text {bound, } I_{0}}$ is the concentration of the $\mathrm{D}_{3}$-tracer bound to the antibody in the absence of competitive inhibitor, $\left[\mathrm{D}_{3} \text {-tracer }\right]_{\text {total }, I_{0}}$ is the total (bound + free) concentration of the $\mathrm{D}_{3}$-tracer in the absence of competitive inhibitor, $\left[\mathrm{D}_{3}\right.$ tracer $]_{\text {sample chamber }}$ is the concentration of the $\mathrm{D}_{3}$-tracer in the sample chamber, and $\left[\mathrm{D}_{3} \text {-tracer }\right]_{\text {buffer chamber }}$ is the concentration of the $\mathrm{D}_{3}$-tracer in the buffer chamber.

For tight-binding antibodies, the $b$ values of the anti-hapten sera were from 0.4 to 0.7 even at high dilutions (1:400, 1:800, and $1: 1600)$. No binding was assigned for anti-hapten sera with $b$ values of $\sim 0 \%$ at 1:25 dilution. The $\%$ inhibition at a given concentration of the competitive inhibitor, $[I$, was calculated using the equation:

$$
\begin{gathered}
\% \text { inhibition }=100 \times\left(1-\frac{\left[\mathrm{D}_{3}-\text { tracer }\right]_{\text {bound }, I}}{\left[\mathrm{D}_{3} \text {-tracer }\right]_{\text {bound }, I_{0}}}\right) \\
{\left[\mathrm{D}_{3} \text {-tracer }\right]_{\text {bound }, I}=\left[\mathrm{D}_{3} \text {-tracer }\right]_{\text {sample chamber }}-\left[\mathrm{D}_{3} \text {-tracer }\right]_{\text {buffer chamber }}}
\end{gathered}
$$

where $\left[\mathrm{D}_{3} \text {-tracer }\right]_{\text {bound, } I}$ is the concentration of the $\mathrm{D}_{3}$-tracer bound to the antibody in the presence of competitive inhibitor. The $K_{\mathrm{d}}$ was not determined at $\leq 1: 100$ dilution due to degradation of heroin, 6-AM, and morphine.

\section{ELISA and competition ELISA}

The pooled mice sera were derived from previous animal studies [25, 29, 30]. ELISA was used to measure the serum antibody levels at week 9 against the heroin haptens. Competition ELISA was used to assess the cross-reactivity of the vaccine-induced anti-hapten sera to heroin and its major metabolites: 6-AM and morphine. ELISA and competition ELISA were performed as described previously [7]. The detailed procedures for ELISA and competition ELISA were provided in the ESM.

\section{Data analysis}

Statistical analysis was performed using GraphPad Prism Version 6.0c. A $t$ test (paired, two-tailed) was used to compare the concentration of the sample and buffer chambers. A one-way analysis of variance (ANOVA) with Tukey's correction for multiple comparisons was used to compare the $K_{\mathrm{d}}$ values derived from different assay conditions and to compare the $\%$ intact heroin after $24 \mathrm{~h}$ from different assay conditions. A oneway ANOVA with anti-DiPrOxyHap as the control group and with Dunnett's correction for multiple comparisons was used to compare the \% bound heroin.

\section{Results}

\section{Synthesis of heroin hapten 6-AcMorHap}

6-AcMorHap was synthesized from hydromorphone 1 using a previously developed procedure for the introduction of the $\mathrm{C}$ 3 nitro group (Fig. 2) [25, 31]. Triflation of the C-3 phenol with $N$-phenyl-trifluoromethansulfonamide followed by palladium-mediated reductive cleavage afforded arene 3 in excellent yield. Direct C-3 nitration was stymied by undesired $\mathrm{C}-1$ regioselectivity of the nitration. Instead, chlorination of the more reactive C-1 position with $N$ chlorosuccinimide allowed for selective C-3 nitration under mild conditions to give nitro compound 5 in moderate yield [32]. The C-6 ketone was reduced with K-selectride to give alcohol 6. Reduction of the nitro group was affected via palladium-catalyzed hydrogenation under acidic conditions, and it proceeded smoothly with concomitant cleavage of the $\mathrm{C}-1$ chlorine to give amino alcohol 7 . The aniline was selectively acylated with 2,5-dioxopyrrolidin1-yl 3-(tritylthio)propanoate 8 to give amide 9 [33]. Finally, acylation of the hydroxyl moiety $\left(\mathrm{Ac}_{2} \mathrm{O}, \mathrm{DMAP}\right)$ afforded heroin hapten 6-AcMorHap in $23 \%$ over eight steps. The syntheses of 6-PrOxyHap, MorHap, DiAmHap, and DiPrOxyHap have been published [25, 30].

\section{Equilibration of $\mathrm{D}_{\mathbf{3}}$-morphine and morphine}

The dialysis cassette consists of two chambers separated by a semipermeable membrane. The $\mathrm{D}_{3}$-tracer was added to the sample chamber while the competitive inhibitor was added to the buffer chamber. $\mathrm{D}_{3}$-morphine ( $5 \mathrm{nM}$, sample chamber) and morphine (1333.3 nM, buffer chamber) were allowed to diffuse in the semipermeable membrane (Fig. 3a, b). At $3 \mathrm{~h}$, $59.68 \pm 2.00$ and $40.32 \pm 2.00 \%$ of $\mathrm{D}_{3}$-morphine partitioned into the sample and buffer chambers, respectively (Fig. 3a), and this difference between the $\% \mathrm{D}_{3}$-morphine in the two chambers was significant $(* * p<0.01, t$ test). There was no significant difference in $\mathrm{D}_{3}$-morphine concentrations between 
Fig. 3 Equilibration of $\mathrm{D}_{3}$ morphine and morphine in dialysis cassettes $(\mathbf{a}, \mathbf{b}) . \mathrm{D}_{3^{-}}$ morphine was added to one side (sample chamber) of the dialysis cassette and morphine to the other side (buffer chamber). $\mathrm{D}_{3^{-}}$ morphine and morphine concentrations reached equilibrium after 6 and $24 \mathrm{~h}$, respectively. Drug concentrations between the two chambers were compared using paired $t$ test $(* * p<0.01, * p<0.05)$. Stability of heroin, 6-AM, and morphine in the absence of sera or in the presence of sera at different sera dilutions in DPBS, pH 7.4 at $4{ }^{\circ} \mathrm{C}$ (c-e). Samples were incubated for the time indicated. No degradation of 6-AM and morphine was observed in the absence of sera. Partial heroin hydrolysis $(\sim 20 \%)$ was observed even in the absence of sera (also shown in Fig. 4a). Opiates were quantified by UPLC/MS/MS. Values are the mean of triplicate determinations \pm standard deviation a

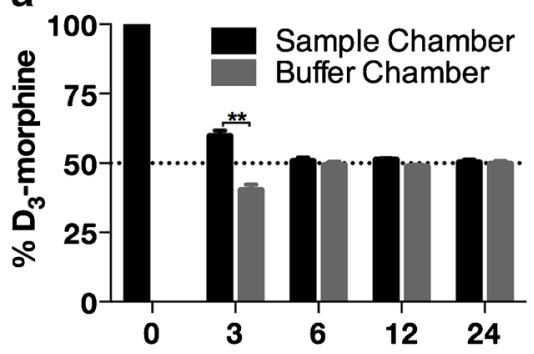

C

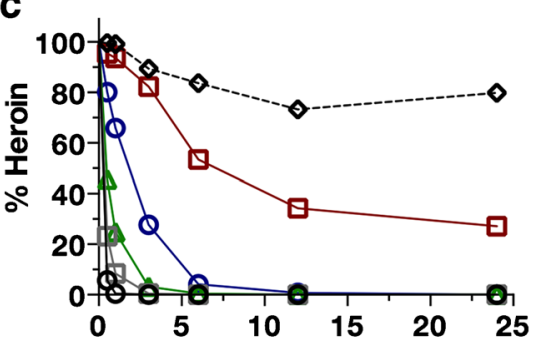

b

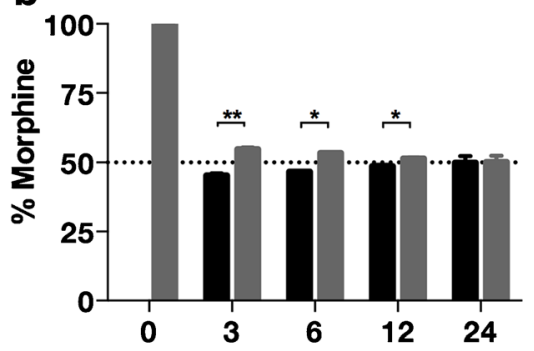

d

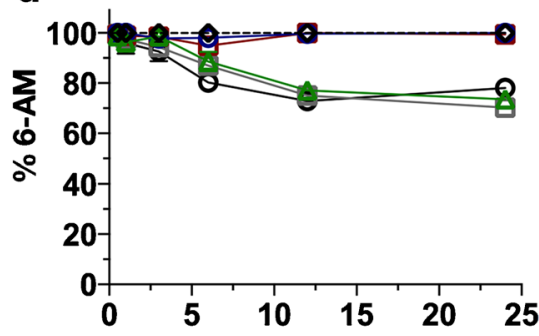

e

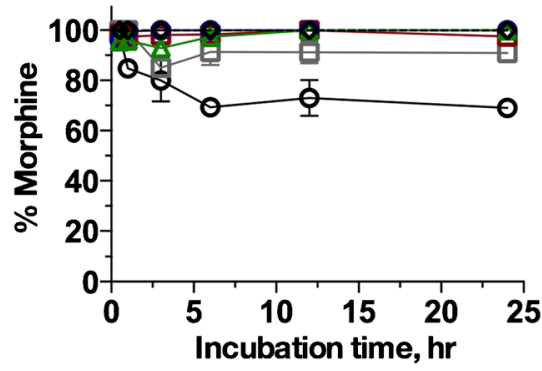

Sera dilution

- no sera

- $1: 25$

七 $1: 50$

$\triangle 1: 100$

- $1: 200$

七 $1: 400$ the sample and buffer chambers at 6,12 , and $24 \mathrm{~h}(p=$ not significant, $t$ test). Also at $3 \mathrm{~h}, 45.32 \pm 0.70$ and $54.66 \pm$ $0.70 \%$ of morphine partitioned into the sample and buffer chambers, respectively (Fig. $3 \mathrm{~b},{ }^{* *} p<0.01, t$ test). The amount of morphine that partitioned into the sample chamber increased over time thereby decreasing the difference between the two chambers: $46.68 \pm 0.17 \%(6 \mathrm{~h}, * p<0.05), 48.59 \pm$ $0.39 \%\left(12 \mathrm{~h},{ }^{*} p<0.05\right)$, and $49.97 \pm 2.3 \%$ ( $24 \mathrm{~h}$, no significant difference compared to the buffer chamber). Based on these data, $24 \mathrm{~h}$ was selected as the standard time of incubation.

\section{Stability of the drugs in dilute sera}

The degradation of heroin, 6-AM, and morphine was examined at different dilutions of the normal mouse sera for $24 \mathrm{~h}$ (Fig. 3c-e). There was an extensive hydrolysis of heroin at all dilutions (Fig. 3c). Thus, the calculation of antibody affinity against heroin was not performed. Hydrolysis of 6-AM was not observed at $\geq 1: 200$ dilutions (Fig. 3d). Degradation of morphine was not observed at $\geq 1: 100$ dilutions (Fig. 3e). Based on stability data and $b$ values (vide infra), the calculation of antibody affinity against 6-AM and morphine was performed at $\geq 1: 400$ dilution.

\section{Apparent dissociation constant of a monoclonal antibody standard}

The $K_{\mathrm{d}}$ of ab1060 at different concentrations of the antibody and the $\mathrm{D}_{3}$-morphine was determined (Table 1). Additionally, parameter $b$, defined as the fraction of the $\mathrm{D}_{3}$-tracer bound to the antibody in the absence of competitive inhibitor, was also considered for the assessment of $K_{\mathrm{d}}$ values. The $K_{\mathrm{d}}(1.96 \pm$ $0.17 \mathrm{nM}$ ) derived from the assay condition with $b=0.41$ was consistent with the reported $K_{\mathrm{d}}(2 \mathrm{nM})$ [34]. Although ED and UPLC/MS/MS have been individually considered as standard methods, this result confirms that the combination of competition ED-UPLC/MS/MS can be accurately used for drugantibody binding quantification. A dramatic reduction in $K_{\mathrm{d}}$ was calculated when $b$ values were outside of this range (Table 1). The results were consistent with the studies of Müller that the performance of competition ED must be done at assay conditions with $b$ values of $0.4-0.7$ [23].

\section{Opiate affinities of vaccine-induced antibodies} by competition ED

For accurate determination of antibody affinity to 6-AM and morphine, the $K_{\mathrm{d}}$ was derived from different dilutions of 
pooled sera, which were obtained by immunization of the indicated hapten conjugated to TT and mixed with liposomal monophosphoryl lipid A as adjuvant (Table 2 and ESM Fig. S4) $[25,29,30,35]$. In general, there was no statistical difference in $K_{\mathrm{d}}$ values when the assay conditions had a $b$ value between 0.4 and 0.7 (ESM Tables S1 and S2). Antibodies to hapten conjugates 6-AcMorHap, 6-PrOxyHap, and MorHap had high affinities $\left(K_{\mathrm{d}}<5 \mathrm{nM}\right)$ to $6-\mathrm{AM}$ and morphine (Table 2). Anti-6-AcMorHap had significantly higher affinities for both 6-AM and morphine relative to anti-6PrOxyHap ( $p<0.05$, one-way ANOVA). Although anti-6PrOxyHap and anti-MorHap had similar affinities to morphine, the affinity of anti-6-PrOxyHap to 6-AM was significantly higher than anti-MorHap ( $p<0.01$, one-way ANOVA). Both anti-DiAmHap and anti-DiPrOxyHap had low affinity for 6-AM and no affinity to morphine. In competition ED, low affinity and no binding were both determined in 1:25 sera dilution also to ensure that the lack of drug-antibody binding was not due to low concentration of the antibody, but due to the affinity of antibody for the drugs. Low affinity is defined as when $>5 \%$ of the $\mathrm{D}_{3}$-tracer was bound to the anti-hapten sera at a $1: 25$ sera dilution but was $<5 \%$ at 1:400. No binding is defined as when $<5 \%$ of the $\mathrm{D}_{3}$-tracer was bound to the anti-hapten sera at 1:25 sera dilution. Antibodies to DiAmHap and DiPrOxyHap bound $61.5 \pm 2.3$ and $9.1 \pm 1.9 \% \mathrm{D}_{3}$-6-AM, respectively, at 1:25 sera dilution. However, the $K_{\mathrm{d}}$ cannot be accurately calculated because 6-AM was relatively unstable at 1:25 sera dilution (Fig. 3d). Both anti-DiAmHap and antiDiPrOxyHap had $0 \%$ binding to $\mathrm{D}_{3}$-morphine at all dilutions (ESM Tables S2 and S3). At 1:400 sera dilution, preimmune sera (week 0) do not bind $\mathrm{D}_{3}-6-\mathrm{AM}$ and $\mathrm{D}_{3}$-morphine,

Table $2 K_{\mathrm{d}}$ of pooled sera from mice immunized with different TThapten conjugates

\begin{tabular}{lll}
\hline Anti-hapten sera & \multicolumn{2}{l}{ Dissociation constant $\left(K_{\mathrm{d}}, \mathrm{nM}\right)^{\mathrm{a}}$} \\
\cline { 2 - 3 } & 6-AM & Morphine \\
\hline 6-AcMorHap & $0.563 \pm 0.05$ & $0.555 \pm 0.08$ \\
6-PrOxyHap & $1.20 \pm 0.19$ & $1.40 \pm 0.16$ \\
MorHap & $2.94 \pm 0.34$ & $1.88 \pm 0.46$ \\
DiAmHap & Low affinity $^{\mathrm{b}}$ & No binding \\
DiPrOxyHap & Low affinity $^{\mathrm{b}}$ & No binding \\
\hline
\end{tabular}

${ }^{\mathrm{a}}$ All $K_{\mathrm{d}}$ values were calculated from the data shown in ESM Fig. S4 using Müller's equation and are the mean of triplicate determinations \pm standard deviation (see ESM, Tables S1 and S2). The affinities of anti-6AcMorHap, anti-6-PrOxyHap, and anti-MorHap for 6-AM are different (multiple comparisons using one-way ANOVA). The affinities of anti-6PrOxyHap and anti-MorHap for morphine are similar and are different to anti-AcMorHap (multiple comparisons using one-way ANOVA)

${ }^{b}>5 \%$ of the $D_{3}$-tracer was bound to the anti-hapten at 1:25 sera dilution but was $<5 \%$ at 1:400 dilution (see ESM, Table S1 and S3)

${ }^{\mathrm{c}}<5 \%$ of the $\mathrm{D}_{3}$-tracer was bound to the anti-hapten at 1:25 sera dilution (see ESM, Tables S2 and S3) confirming that plasma proteins were not binding the opiates used in this study.

\section{Binding of heroin to vaccine-induced antibodies}

The $K_{\mathrm{d}}$ of polyclonal antibodies to heroin cannot be measured by competition ED-UPLC/MS/MS utilizing $\mathrm{D}_{3}$-heroin because of the extensive degradation of heroin in dilute sera. By extrapolation of the heroin stability data during ED with 1:400 sera dilution (Figs. $3 \mathrm{c}$ and $4 \mathrm{a}$ ), heroin, $\mathrm{D}_{3}$-heroin, 6-AM, and $\mathrm{D}_{3}-6$ $\mathrm{AM}$ would be present at equilibrium with 6-AM and $\mathrm{D}_{3}-6-\mathrm{AM}$ as predominant chemical species. Although $K_{\mathrm{d}}$ cannot be accurately calculated, the assessment of heroin binding to polyclonal antibody is feasible if sufficient concentration of heroin is present in the assay. After $24 \mathrm{~h}, 79.9 \pm 2.71 \%$ heroin remained intact in DPBS (Fig. 4a). This observation was consistent with a previous report on the spontaneous hydrolysis of heroin at physiological $\mathrm{pH}$ [36]. This indicates that assay conditions must be identified such that the degradation of heroin in given serum dilution is comparable to spontaneous hydrolysis of heroin in buffer. The effect of inhibitors $(I)$ on the stability of heroin was determined by measuring \% intact heroin after $24 \mathrm{~h}$ in DPBS (Sera), in dilute sera (+ Sera), and in dilute sera in the presence of OMPA/BNPP (+ Sera/ $I)$. The inhibitors did not suppress the spontaneous hydrolysis of heroin in buffer ( $p=$ not significant, one-way ANOVA) but did inhibit the extensive degradation of heroin in sera $(* * * * p<0.0001$, one-way ANOVA). The binding of heroin to anti-hapten sera was measured in the presence of inhibitors because the inhibitors blocked the serum esterasemediated heroin degradation allowing for appreciable heroin concentrations that can be measured under these assay conditions. ED performed in the presence of these inhibitors showed that anti-6-AcMorHap, anti-6-PrOxyHap, anti-MorHap, and anti-DiAmHap bound significantly higher amount of heroin with $92.89 \pm 0.72 \%(* * * * p<0.0001), 76.66 \pm 2.17 \%$ $(* * * * p<0.0001), 13.82 \pm 4.66 \%(* * p<0.01)$, and $10.75 \pm 5.34$ ( ${ }^{*} p<0.05$, one-way ANOVA), respectively, relative to antiDiPrOxyHap (1.54 $\pm 2.66 \%$ ) (Fig. 4b, multiple comparisons using one-way ANOVA).

\section{Opiate affinities of vaccine-induced antibodies by competition ELISA}

The most commonly used method for measuring the affinity of anti-hapten sera to small molecules has been competition ELISA because of its facile nature. In competitive ELISA, binding affinity is reported in terms of $50 \%$ inhibition concentration $\left(\mathrm{IC}_{50}\right)$. Analysis of the anti-hapten sera by competition ELISA indicated that anti-6-AcMorHap and anti-6PrOxyHap had the highest relative affinities $\left(\mathrm{IC}_{50}<10 \mu \mathrm{M}\right)$ to heroin, 6-AM, and morphine (Table 3 and ESM Fig. S11). Anti-MorHap showed more modest affinity $\left(\mathrm{IC}_{50} \sim 21 \mu \mathrm{M}\right)$ to 6-AM, higher affinity for morphine $(9.2 \mu \mathrm{M})$, and no affinity 


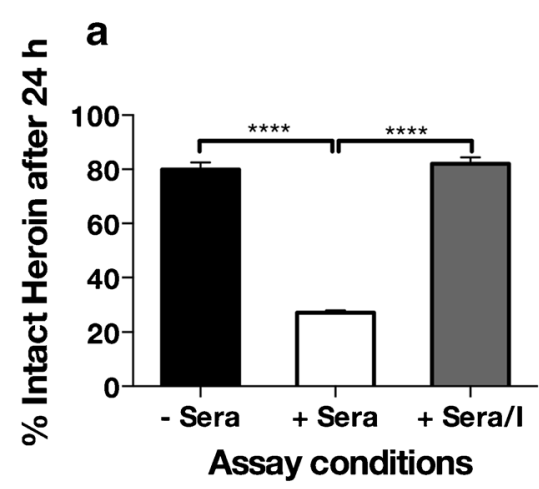

Fig. 4 Assessment of the anti-hapten binding to heroin. Percent of intact heroin after $24 \mathrm{~h}$ in buffer with no sera (- Sera, DPBS), with sera (+ Sera, 1:400 sera dilution in DPBS), and with sera and inhibitors ( + Sera/ $I, 1: 400$ sera dilution in DPBS containing the esterase inhibitors iso-OMPA/ BNPP) (a). Percent heroin in - Sera and + Sera/I was similar and different from + Sera $(* * * * p<0.0001$, multiple comparisons using one-way ANOVA). Percent of heroin that was bound to anti-hapten sera in the

$\left(\mathrm{IC}_{50}>10^{3} \mu \mathrm{M}\right)$ to heroin. Anti-DiAmHap had no affinity for heroin and its metabolites. Anti-DiPrOxyHap displayed modest affinity to heroin, lower affinity to 6-AM $\left(\mathrm{IC}_{50} \sim 145 \mu \mathrm{M}\right)$, and no affinity to morphine. Comparison of these affinities with those obtained by competition ED-UPLC/MS/MS indicated that the affinity $\left(\mathrm{IC}_{50}\right)$ derived from competition ELISA underestimated the actual $K_{\mathrm{d}}$ value by a factor of $10^{3}-10^{4}$. Competition ELISA did not determine if the antibodies bind the drug of interest or if the degradation product was responsible for the binding (i.e., heroin degrading to 6-AM).

\section{Discussion}

Drugs of abuse are too small to elicit antibody production and, therefore, require conjugation of structural analogs (haptens)

Table 3 Antibody titer and $\mathrm{IC}_{50}$ calculated using competition ELISA of pooled sera from mice immunized with different TT-hapten conjugates

\begin{tabular}{lllll}
\hline Anti-hapten sera & Endpoint antibody titer & \multicolumn{2}{l}{$\begin{array}{l}\text { Inhibition concentration } \\
\left(\mathrm{IC}_{50}, \mu \mathrm{M}\right)^{\mathrm{b}}\end{array}$} \\
\cline { 3 - 5 } & & Heroin & 6-AM & Morphine \\
\hline 6-AcMorHap & 819,200 & 0.5 & 1.1 & 0.1 \\
6-PrOxyHap & 409,600 & 2.2 & 7.5 & 1.6 \\
MorHap & $1,638,400$ & $>1000$ & 21.41 & 9.182 \\
DiAmHap & 204,800 & $>1000$ & $>1000$ & $>1000$ \\
DiPrOxyHap & 102,400 & 16.8 & 144.9 & $>1000$ \\
\hline
\end{tabular}

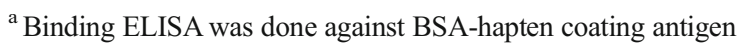

${ }^{\mathrm{b}} \mathrm{All} \mathrm{IC}_{50}$ values were calculated from competition ELISA data shown in ESM Fig. S11 using nonlinear regression log [inhibitor] vs. normalized response model b

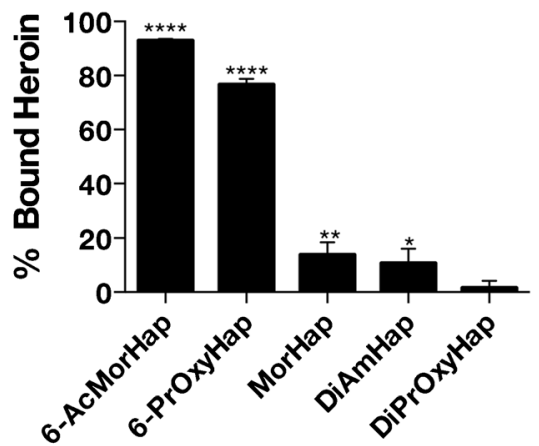

Anti-hapten sera

presence of iso-OMPA/BNPP (b). Percent bound heroin was different from anti-DiPrOxyHap sera $\left(* * * * p<0.0001,{ }^{* *} p<0.01,{ }^{*} p<0.05\right.$, multiple comparisons using one-way ANOVA). Opiates were quantified by UPLC-MS/MS. Sera from week 9 (3 weeks after two immunizations) from five mice per group were pooled and used in the assays. Values are the mean of triplicate determinations \pm standard deviation

to immunogenic proteins $[37,38]$. Hapten bioconjugate vaccines are frequently used to generate functional antibodies against small molecules. The chemical structure of the hapten generally dictates the cross-reactivity of the anti-hapten sera, and thus, the hapten surrogate must be rationally designed [ 30 , $39,40]$. To be efficacious, the hapten antibodies must crossreact with high affinity to the target drug(s).

For heroin vaccines, the hapten design must mimic the key epitopes of heroin and its metabolites [4]. Currently, there has been no established rule that predicts whether a given hapten design would induce anti-hapten sera that target multiple chemical structures. To better understand the relationship between structure and cross-reactivity, the binding affinity of the antibodies induced by immunization with heroin haptens 6AcMorHap, 6-PrOxyHap, MorHap, DiAmHap, and DiPrOxyHap conjugated to TT (Fig. 2) was assessed using competition ED-UPLC/MS/MS and competition ELISA (Fig. 5). We hypothesized that these hapten designs will induce antibodies with different cross-reactivities that will guide the future optimization of hapten structure. In terms of linker point attachment, the hapten design can be assigned into three groups: C3-linked haptens (6-AcMorHap and 6-PrOxyHap), C6-linked hapten (MorHap), and N-linked haptens (DiAmHap and DiPrOxyHap). The importance of linker point attachment was previously discussed by Matyas' concept on facial recognition [30]. The conjugation of the haptenic surrogates to TT confines their freedom of motion, and thus, the hapten's molecular structure bisects into two immunologically defined "faces." The "front face" is defined as the key epitopes exposed to the immune system, while the "back face" is the sterically blocked moieties that cannot induce antibodies. Using the concept of facial recognition, 6-AcMorHap is particularly interesting because it preserves the C6-ester group 


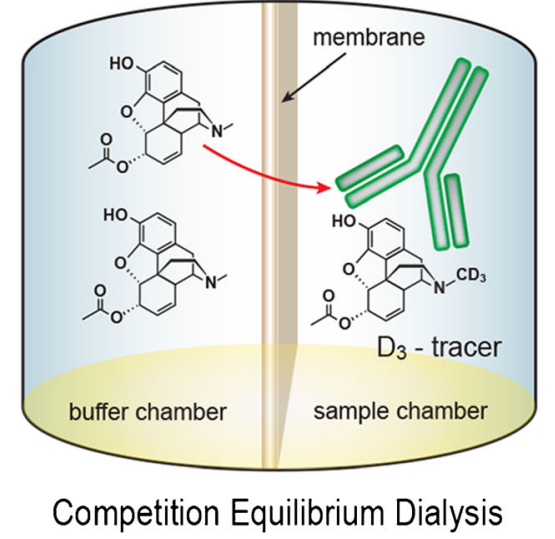

Fig. 5 Comparison of competition ED and competition ELISA. In this example, the affinity of the anti-6-AcMorHap to 6-AM is measured. For competition $\mathrm{ED}, 6-\mathrm{AM}$ is allowed to equilibrate with $\mathrm{D}_{3}-6-\mathrm{AM} /$ anti-6AcMorHap. At equilibrium, the amount of drugs in both chambers is quantified by UPLC/MS/MS (left panel). For competition ELISA, the

that is the common moiety for both heroin and 6-AM [30]. Animals immunized with $\mathrm{C} 3$-linked hapten conjugates induced antibodies that bind morphine [41, 42]. In contrast to 6-AcMorHap, the haptens that were used by Spector and Koida contain a C6-alcohol group. We hypothesized that 6AcMorHap has a "front face" that mimics heroin, 6-AM, and morphine, and thus, TT-6-AcMorHap bioconjugates will induce antibodies that cross-react with these three drugs (Fig. 1a, b) [30]. We also hypothesized that modification of an acetyl group to a propan-2-one group at the C6 position (i.e., 6-PrOxyHap) will reduce the binding affinity, but will not change the pattern of cross-reactivity because haptens 6AcMorHap and 6-PrOxyHap have similar overall molecular shapes. Previously, we were not able to accurately measure the affinity of the anti-hapten sera due to the inherent limitations of competition ELISA [30]. Now that we can more accurately measure the affinity, we are able to demonstrate that our hypothesis of facial recognition has greater relevance [30].

In this study, competition $\mathrm{ED}$ utilizing $\mathrm{D}_{3}$-tracers has been developed to address the inherent constraints of competition ELISA. The main challenge in ED is to maintain the stability of the heroin and its metabolites during the assay. To address this problem, the equilibration time and the degradation of the drugs in dilute sera were investigated. Equilibration between the competitive inhibitor and the $\mathrm{D}_{3}$-tracer were attained at $24 \mathrm{~h}$ (Fig. 3a, b). However, this long equilibration time is not compatible with the short half-life of heroin and its metabolites in "neat" sera. We believed that by diluting the mouse sera, the concentration of the enzymes involved in heroin metabolism would be reduced. Consequently, the degradation of heroin and its metabolites would be suppressed. The degradation of the drugs in different dilutions of the sera was monitored for $24 \mathrm{~h}$ (Fig. 3c-e). At all dilutions, extensive degradation of heroin was observed. This suggests that the activity of the esterases, which are responsible for $\mathrm{C} 3$-ester

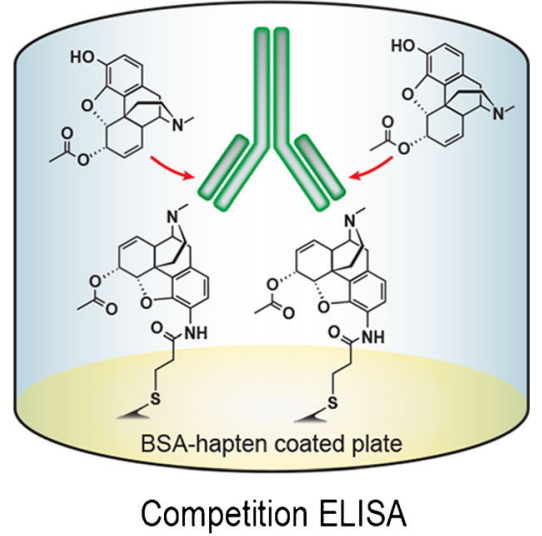

ELISA plate wells are precoated with bovine serum albumin (BSA)-6AcMorHap and subsequently incubated with anti-6-AcMorHap. 6-AM is allowed to disrupt the BSA-6-AcMorHap/anti-6-AcMorHap interactions (right panel). The synthesis of BSA-6-AcMorHap was described in the ESM and Fig. S12

group cleavage, cannot be suppressed by simple dilution. After $24 \mathrm{~h}$, degradation of 6-AM and morphine was observed at lower dilutions but not at higher dilutions of sera. This indicates that the activity of the enzymes responsible for C6-ester group hydrolysis is concentration dependent. In general, morphine metabolism occurs in the liver. However, extrahepatic metabolism of morphine has been also reported [43]. The degradation profiles of the drugs seem to reach a plateau after $12 \mathrm{~h}$, which might be due to loss of enzymatic activity. Collectively, $\geq 1: 400$ sera dilutions can be used to measure antibody affinities to 6-AM and morphine but not to heroin.

Another challenge that must be addressed in ED is the potential impact of plasma protein binding of the drugs. Recently, Zhang et al. reported the plasma protein binding of 222 drugs, of which $50 \%$ showed $90-100 \%$ binding [44]. In "neat" plasma/sera, heroin and morphine have $~ 35 \%$ plasma binding [45]. Presumably, 6-AM will also have $~ 35 \%$ plasma binding due to structural similarity to both drugs. If the binding of the $\mathrm{D}_{3}$-tracers to plasma protein is significant, the distinction of bonafide antibody-drug interactions from nonspecific protein binding becomes challenging. However, we believed that the effect of plasma binding could be reduced by sera dilution. At $\geq 1: 400$ dilution of the week 0 sera (i.e., preimmunized sera), $\mathrm{D}_{3}-6$-AM and $\mathrm{D}_{3}$-morphine showed $\sim 0 \%$ binding to the plasma proteins. The binding of heroin to plasma proteins cannot be accurately assessed due to esterase-mediated degradation of heroin in dilute sera. However, extrapolation of the \% bound heroin for antiDiPrOxyHap sera conveys that the binding of heroin to plasma proteins is negligible in 1:400 sera dilution (Fig. 4b). Collectively, these data suggest that competition ED-UPLC/MS/ MS can be used to measure antibody affinities to 6-AM and morphine in the dilute sera. For other drugs, where plasma protein binding is still significant even in dilute sera, the $K_{\mathrm{d}}$ values would difficult to calculate. 
We tested the applicability of the competition ED-UPLC/ MS/MS method for evaluating small drug-antibody interactions by measuring the dissociation constant of commercially available morphine monoclonal antibody ab1060. According to Müller, competition equilibrium dialysis should be carried out under the following conditions: (1) the $b$ value of the antibody/ tracer system should be $\sim 0.4-0.7$, and (2) the specific radioactivity of the tracer should be optimal to prevent large deviations in the antibody affinity [23]. The effects of $b$ values and $\mathrm{D}_{3}$ morphine concentrations on $K_{\mathrm{d}}$ were investigated using different assay conditions. Our results were consistent with the findings of Müller. A $K_{\mathrm{d}}$ of $1.96 \mathrm{nM}$, which is in agreement with the reported value of $2 \mathrm{nM}$ [34], is obtained for ab1060 when $b$ is 0.41 (Table 1 and ESM Fig. S4). At $2.4 \mathrm{nM}$ ab1060/2.5 nM D $3^{-}$ morphine, a large deviation in $K_{\mathrm{d}}$ was observed. This most likely was because $b$ was $>0.7$ and $2.5 \mathrm{nM} \mathrm{D}_{3}$-morphine was not an optimal tracer concentration. Considering the accuracy of affinity is dependent on both $b$ values and specific concentration of the tracer, we utilized the $b$ limit range of $0.4-0.7$ and $5 \mathrm{nM} \mathrm{D}_{3}$ tracer for determining the $K_{\mathrm{d}}$ values of the anti-hapten sera.

Since antibody concentration is not required for the calculation of affinity, the competition ED-UPLC MS/MS could be extended to polyclonal sera [23]. As the polyclonal sera have high antibody titer (Table 3), we hypothesized that the concentration of hapten antibodies in dilute sera is still amenable for binding studies. The $b$ values of anti-hapten sera were determined at both low and high sera dilutions (ESM Tables S1-S3). Anti-6-AcMorHap, anti-6-PrOxyHap, and anti-MorHap had $b$ values of $0.4-0.7$ at the range of 1:4001:1600 dilutions. This suggests that $K_{\mathrm{d}}$ for 6-AM and morphine can be only calculated within a specific dilution range. At low sera dilution $(\leq 1: 100), 6$-AM and morphine were prone to degradation, while at high sera dilution $(\geq 1: 1600, b$ $<0.4$ ), the concentration of antibody was insufficient for reliable quantification. Anti-6-AcMorHap, anti-6-PrOxyHap, and anti-MorHap bound 6-AM and morphine with $K_{\mathrm{d}}$ values of $<5 \mathrm{nM}$ (Table 2 and ESM Fig. S4). Both anti-DiAmHap and anti-DiPrOxyHap have low affinity for 6-AM and no affinity for morphine. In contrast to the affinity values derived from ab1060, the $K_{\mathrm{d}}$ values of anti-hapten sera were not prone to large deviations when $b \geq 0.7$. Based on the results, "pure" monoclonal antibody was more sensitive to variation in $K_{\mathrm{d}}$, when the $b$ values were outside of the limit range. As the study of Müller was performed using anti-hapten polyclonal sera, the $b$ limits of $0.4-0.7$ might have limitations when applied to monoclonal antibodies. It is also possible that the optimal range of $b$ values and $\mathrm{D}_{3}$-tracer concentrations vary from a given specific monoclonal antibody/drug system to another, and therefore, these values have to be determined empirically. In the case of the polyclonal anti-hapten sera that were used in this study, the $b$ limit range of $0.4-0.7$ was congruent with the findings of Müller, and the 5-nM D $\mathrm{D}_{3}$-tracer concentration was optimal enough to prevent large deviation in $K_{\mathrm{d}}$ values.
To suppress the hydrolysis of heroin at 1:400 sera dilution, the specific esterase inhibitors iso-OMPA and BNPP were added to the reaction mixture [46-48]. The addition of isoOMPA and BNPP increased the amount of intact heroin to $\geq 80 \%$, which was comparable to hydrolysis of heroin in DPBS in the absence of sera (Fig. 4a). This suggests that although $K_{\mathrm{d}}$ could not be calculated, the amount of $\%$ bound heroin to the antibody in lieu of $K_{\mathrm{d}}$ could be used to assess binding. Anti-6-AcMorHap and anti-6-PrOxyHap had 92.89 \pm 0.72 and $76.66 \pm 2.17 \%$ of the heroin bound, respectively (Fig. 4b), suggesting that hapten designs 6-AcMorHap and 6PrOxyHap can mimic crucial epitopes of heroin.

While competition ED is a solution-based assay, competition ELISA depends on interactions at the solid-liquid interface (Fig. 5). In contrast to the competition ED-UPLC/MS/ MS method, the $\mathrm{IC}_{50}$ values calculated from competition ELISA were in the micromolar range, which suggest low affinity antibodies (Table 3 and ESM Fig. S11). Collectively, the $\mathrm{IC}_{50}$ values derived from competition ELISA were $10^{3}-10^{4}$ higher than the $K_{\mathrm{d}}$ from competition ED-UPLC/MS/MS. However, we believe that these $\mathrm{IC}_{50}$ values are not true reflections of drug-antibody interactions. In competition ELISA, hapten-antibody interactions occur at the solid-liquid interface and, thus, are prone to avidity effects. It could be envisioned that the two arms of the IgG antibodies were tightly engaged to the haptens of the coating antigen; thus, higher concentrations of the competing drugs are needed to disrupt the haptenantibody interactions. Besides underestimation of antibody affinity (i.e., high $\mathrm{IC}_{50}$ ), another limitation associated with competition ELISA is ambiguity in the interpretation of results. In the case of anti-DiAmHap, there are at least two interpretations for $\mathrm{IC}_{50}>10^{3} \mu \mathrm{M}$. As we originally proposed for anti-DiAmHap and anti-DiPrOxyHap, either the hapten antibodies simply do not cross-react with the competing drugs, or the affinity of the hapten antibodies to the original hapten design is extremely high $[25,30]$. The latter interpretation is consistent with our previous findings [30] and the findings of Pravetoni et al., which demonstrated the higher affinity of hapten antibodies to haptenic surrogate than the target drugs [15]. In addition, the avidity effects associated with competition ELISA further increase the interactions between the haptenic surrogate and the hapten antibodies. This ambiguity can be resolved by considering the $b$ values derived from competition ED-UPLC/MS/MS (ESM Tables S1-S3). Extending those findings, the $\mathrm{IC}_{50}$ values of anti-DiAmHap and anti-DiPrOxyHap to 6-AM and morphine are simply due to weak drug-antibody interactions.

Although there was an underestimation of binding affinities (i.e., high $\mathrm{IC}_{50}$ ) with competition ELISA [14], it is noteworthy to mention that both methods gave similar trends, i.e., polyclonal antibody with high binding affinities for heroin, 6AM, and morphine was consistently predicted by both methods. In light of the results, we have observed recurring 
themes that could serve as guiding principles in the design of a heroin vaccine (Fig. 1b). First, when linker is at the $\mathrm{C} 3$ position, the induced antibodies (anti-6-AcMorHap and anti-6PrOxyHap) cross-reacted with heroin, 6-AM, and morphine. Second, when linker is at the C6 position, the induced antibodies (anti-MorHap) cross-reacted with both 6-AM and morphine, but poorly with heroin. Third, when the linker is at the bridge nitrogen, the induced antibodies (anti-DiAmHap and anti-DiPrOxyHap) had low cross-reactivity to both 6-AM and morphine. Heroin contains two acetyl groups at the $\mathrm{C} 3$ and $\mathrm{C} 6$ position, while DiAmHap and DiPrOxyHap have acetamide and propan-2-one groups, respectively. The binding affinity data suggest that modifications at this position dramatically affect the cross-reactivity of the induced antibodies to heroin. These results are in agreement with previous reports that hydrolytically stable N-linked haptens tended to generate antibodies that were highly specific to the parent hapten and had no cross-reactivity to other drugs [49-52]. It has been postulated that antibody titer and antibody affinity are crucial for the efficacy of drug of abuse vaccines [1,2]. Previously, we demonstrated that mice immunized with TT-DiAmHap and TTDiPrOxyHap showed partial protection and no protection against heroin challenge, respectively $[25,30]$. In terms of binding affinity, anti-DiAmHap is superior to antiDiPrOxyHap (Fig. 4b and ESM Table S3). The protection against heroin challenge could be attributed to the presence of high titer, but low affinity antibodies to heroin and 6-AM. Based on $\mathrm{IC}_{50}$ and antibody titer from ELISA and $K_{\mathrm{d}}$ and \% heroin bound from competition ED-UPLC/MS/MS, it is clear that 6-AcMorHap and 6-PrOxyHap are the lead hapten designs.

Despite the ability of competition ED-UPLC/MS/MS to measure $K_{\mathrm{d}}$, the assay system does have some limitations. Due to the use of dilute sera, the method cannot measure the affinity of polyclonal antibodies that poorly bind 6-AM and morphine. Within the context of a heroin vaccine, it can be argued that the determination of antibodies with high $K_{\mathrm{d}}$ values ( $>1 \mu \mathrm{M}$, low affinity antibodies) is unimportant, since these antibodies are expected to bind low amounts of heroin and its metabolites and, consequently, have little role in efficacy. The competition ED-UPLC/MS/MS also cannot be used for drugs that have a significant binding to plasma proteins even at high sera dilutions. Overall, competition ED-UPLC/ MS/MS is a simple method for determining the binding affinities of antibodies. It is a convenient method because it does not involve the use of radioactive tracers, and all the reagents for the assay are commercially available. This nonradioactive method only requires $5-10 \mu \mathrm{L}$ of anti-hapten sera to generate a binding curve and has the potential applications for studying the binding affinities of antibodies induced by small molecule hapten-based immunogens. In addition, competition EDUPLC/MS/MS resolved the ambiguity of the $\mathrm{IC}_{50}$ values derived from competition ELISA.
Acknowledgments The work of JFGA, FL, AEJ, and KCR was supported by the NIH Intramural Research Programs of the National Institute on Drug Abuse and the National Institute of Alcohol Abuse and Alcoholism. The work of OBT, RJ, CRA, and GRM was supported through a Cooperative Agreement Award (no. W81XWH-07-2-067) between the Henry M. Jackson Foundation for the Advancement of Military Medicine and the U.S. Army Medical Research and Materiel Command (MRMC). The work was partially supported by an Avant Garde award to GRM from the National Institute on Drug Abuse (NIH grant no. 1DP1DA03478701). We thank Noel Whittaker and Dr. John Lloyd (Mass Spectrometry Facility, NIDDK) for the mass spectral data and Drs. Klaus Gawrisch and Walter Teague (Laboratory of Membrane Biochemistry and Biophysics, NIAAA) for NMR spectroscopic data. We also thank Dr. Kejun Cheng (FDA) for providing some of the initial compounds and Mr. Marcus Gallon, Ms. Caroline Kittinger, Ms. Courtney Tucker, and Mr. Alexander Duval for providing outstanding technical assistance. Research was conducted in compliance with the Animal Welfare Act and other federal statutes and regulations relating to animals and experiments involving animals and adhered to the principles stated in the Guide for the Care and Use of Laboratory Animals, NRC Publication, 1996 edition.

\section{Compliance with ethical standards}

Conflict of interest The authors declare that they have no competing interests. However, Gary R. Matyas, Kenner C. Rice, Arthur E. Jacobson, and Carl R. Alving are coinventors in a related patent application that is owned by Walter Reed Army Institute of Research, National Institute on Drug Abuse, and Henry M. Jackson Foundation.

Disclaimer The views expressed in this article are those of the authors and do not necessarily reflect the official policy of the Department of the Army, Department of Defense, or NIH, or the U.S. Government.

Open Access This article is distributed under the terms of the Creative Commons Attribution 4.0 International License (http:// creativecommons.org/licenses/by/4.0/), which permits unrestricted use, distribution, and reproduction in any medium, provided you give appropriate credit to the original author(s) and the source, provide a link to the Creative Commons license, and indicate if changes were made.

\section{References}

1. Kosten TR, Domingo CB (2013) Can you vaccinate against substance abuse? Expert Opin Biol Ther 13:1093-1097

2. Janda KD, Treweek JB (2012) Vaccines targeting drugs of abuse: is the glass half-empty or half-full? Nat Rev Immunol 12:67-72

3. Rook EJ, van Ree JM, van den Brink W, Hillebrand MJ, Huitema AD, Hendriks VM, Beijnen JH (2006) Pharmacokinetics and pharmacodynamics of high doses of pharmaceutically prepared heroin, by intravenous or by inhalation route in opioid-dependent patients. Basic Clin Pharmacol Toxicol 98:86-96

4. Stowe GN, Schlosburg JE, Vendruscolo LF, Edwards S, Misra KK, Schulteis G, Zakhari JS, Koob GF, Janda KD (2011) Developing a vaccine against multiple psychoactive targets: a case study of heroin. CNS Neurol Disord: Drug Targets 10:865-875

5. Bogen IL, Boix F, Nerem E, Morland J, Andersen JM (2014) A monoclonal antibody specific for 6-monoacetylmorphine reduces acute heroin effects in mice. J Pharmacol Exp Ther 349: 568-576

6. Carroll FI, Blough BE, Pidaparthi RR, Abraham P, Gong PK, Deng L, Huang X, Gunnell M, Lay JO Jr, Peterson EC, Owens SM (2011) Synthesis of mercapto-(+)-methamphetamine haptens and their use 
for obtaining improved epitope density on $(+)$-methamphetamine conjugate vaccines. J Med Chem 54:5221-5228

7. Jalah R, Torres OB, Mayorov AV, Li F, Antoline JF, Jacobson AE, Rice KC, Deschamps JR, Beck Z, Alving CR, Matyas GR (2015) Efficacy, but not antibody titer or affinity, of a heroin hapten conjugate vaccine correlates with increasing hapten densities on tetanus toxoid, but not on CRM197 carriers. Bioconjug Chem 26:10411053

8. Engvall E, Perlmann P (1971) Enzyme-linked immunosorbent assay (ELISA). Quantitative assay of immunoglobulin G. Immunochemistry 8:871-874

9. Van Weemen BK, Schuurs AH (1971) Immunoassay using antigenenzyme conjugates. FEBS Lett 15:232-236

10. Engvall E, Perlmann P (1972) Enzyme-linked immunosorbent assay, ELISA. 3. Quantitation of specific antibodies by enzymelabeled anti-immunoglobulin in antigen-coated tubes. J Immunol 109:129-135

11. Plested JS, Coull PA, Gidney MA (2003) ELISA. Methods Mol Med 71:243-261

12. Devey ME, Bleasdale K, Lee S, Rath S (1988) Determination of the functional affinity of IgG1 and IgG4 antibodies to tetanus toxoid by isotype-specific solid-phase assays. J Immunol Methods 106:119125

13. Rath S, Stanley CM, Steward MW (1988) An inhibition enzyme immunoassay for estimating relative antibody affinity and affinity heterogeneity. J Immunol Methods 106:245-249

14. Bremer PT, Schlosburg JE, Lively JM, Janda KD (2014) Injection route and TLR9 agonist addition significantly impact heroin vaccine efficacy. Mol Pharmaceutics 11:1075-1080

15. Pravetoni M, Keyler DE, Pidaparthi RR, Carroll FI, Runyon SP, Murtaugh MP, Earley CA, Pentel PR (2012) Structurally distinct nicotine immunogens elicit antibodies with non-overlapping specificities. Biochem Pharmacol 83:543-550

16. Way EL, Kemp JW, Young JM, Grassetti DR (1960) The pharmacologic effects of heroin in relationship to its rate of biotransformation. J Pharmacol Exp Ther 129:144-154

17. Lockridge O, Mottershaw-Jackson N, Eckerson HW, La Du BN (1980) Hydrolysis of diacetylmorphine (heroin) by human serum cholinesterase. J Pharmacol Exp Ther 215:1-8

18. Owen JA, Nakatsu K (1983) Diacetylmorphine (heroin) hydrolases in human blood. Can J Physiol Pharmacol 61:870-875

19. Salmon AY, Goren Z, Avissar Y, Soreq H (1999) Human erythrocyte but not brain acetylcholinesterase hydrolyses heroin to morphine. Clin Exp Pharmacol Physiol 26:596-600

20. Redinbo MR, Bencharit S, Potter PM (2003) Human carboxylesterase 1: from drug metabolism to drug discovery. Biochem Soc Trans 31:620-624

21. Torres OB, Jalah R, Rice KC, Li F, Antoline JF, Iyer MR, Jacobson AE, Boutaghou MN, Alving CR, Matyas GR (2014) Characterization and optimization of heroin hapten-BSA conjugates: method development for the synthesis of reproducible hapten-based vaccines. Anal Bioanal Chem 406:5927-5937

22. Wu G (2010) Assay development: fundamentals and practices. Wiley, Hoboken

23. Müller R (1983) Determination of affinity and specificity of antihapten antibodies by competitive radioimmunoassay. Methods Enzymol 92:589-601

24. Pichini S, Altieri I, Pellegrini M, Zuccaro P, Pacifici R (1999) The role of liquid chromatography-mass spectrometry in the determination of heroin and related opioids in biological fluids. Mass Spectrom Rev 18:119-130

25. Li F, Cheng K, Antoline JF, Iyer MR, Matyas GR, Torres OB, Jalah R, Beck Z, Alving CR, Parrish DA, Deschamps JR, Jacobson AE, Rice KC (2014) Synthesis and immunological effects of heroin vaccines. Org Biomol Chem 12:7211-7232
26. Droupadi PR, Meyers EA, Linthicum DS (1994) Spectroscopic evidence for charge-transfer complexation in monoclonal antibodies that bind opiates. J Protein Chem 13:297-306

27. Gottas A, Oiestad EL, Boix F, Ripel A, Thaulow CH, Pettersen BS, Vindenes V, Morland J (2012) Simultaneous measurement of heroin and its metabolites in brain extracellular fluid by microdialysis and ultra performance liquid chromatography tandem mass spectrometry. J Pharmacol Toxicol Methods 66:14-21

28. Fahnestock ML, Johnson JL, Feldman RM, Tsomides TJ, Mayer J, Narhi LO, Bjorkman PJ (1994) Effects of peptide length and composition on binding to an empty class I MHC heterodimer. Biochemistry 33:8149-8158

29. Matyas GR, Mayorov AV, Rice KC, Jacobson AE, Cheng K, Iyer MR, Li F, Beck Z, Janda KD, Alving CR (2013) Liposomes containing monophosphoryl lipid A: a potent adjuvant system for inducing antibodies to heroin hapten analogs. Vaccine 31:2804-2810

30. Matyas GR, Rice KC, Cheng K, Li F, Antoline JF, Iyer MR, Jacobson AE, Mayorov AV, Beck Z, Torres OB, Alving CR (2014) Facial recognition of heroin vaccine opiates: type 1 crossreactivities of antibodies induced by hydrolytically stable haptenic surrogates of heroin, 6-acetylmorphine, and morphine. Vaccine 32: 1473-1479

31. Csuk R, Vasileva G, Barthel A (2012) Towards an efficient preparation of hydromorphone. Synthesis 44:2840-2842

32. Uemura S, Toshimitsu A, Okano M (1978) Nitration of aromatic hydrocarbons and ipso-nitrosodemetallation of arylmetal compounds in sodium nitrite-trifluoroacetic acid. J Chem Soc Perkin Trans 1:1076-1079

33. Galibert M, Renaudet O, Dumy P, Boturyn D (2011) Access to biomolecular assemblies through one-pot triple orthogonal chemoselective ligations. Angew Chem Int Ed Engl 50:1901-1904

34. Information on anti-morphine antibody (ab1060). http://www. abcam.com/morphine-antibody-ab1060.html. Accessed on 23 June 2015

35. Alving CR, Matyas GR, Torres O, Jalah R, Beck Z (2014) Adjuvants for vaccines to drugs of abuse and addiction. Vaccine 32:5382-5389

36. Smith PT, Hirst M, Gowdey CW (1978) Spontaneous hydrolysis of heroin in buffered solution. Can J Physiol Pharmacol 56:665-667

37. Landsteiner K, Jacobs J (1935) Studies on the sensitization of animals with simple chemical compounds. J Exp Med 61:643-656

38. Landsteiner K, Jacobs J (1936) Studies on the sensitization of animals with simple chemical compounds II. J Exp Med 64:625-639

39. Stowe GN, Vendruscolo LF, Edwards S, Schlosburg JE, Misra KK, Schulteis G, Mayorov AV, Zakhari JS, Koob GF, Janda KD (2011) A vaccine strategy that induces protective immunity against heroin. J Med Chem 54:5195-5204

40. Pryde DC, Jones LH, Gervais DP, Stead DR, Blakemore DC, Selby MD, Brown AD, Coe JW, Badland M, Beal DM, Glen R, Wharton Y, Miller GJ, White P, Zhang N, Benoit M, Robertson K, Merson JR, Davis HL, McCluskie MJ (2013) Selection of a novel antinicotine vaccine: influence of antigen design on antibody function in mice. PLoS One 8, e76557

41. Spector S, Parker CW (1970) Morphine: radioimmunoassay. Science 168:1347-1348

42. Koida M, Takahashi M, Kaneto H (1974) The morphine 3glucuronide directed antibody: its immunological specificity and possible use for radioimmunoassay of morphine in urine. Jpn $\mathrm{J}$ Pharmacol 24:707-714

43. Hoskin PJ, Hanks GW (1990) Morphine: pharmacokinetics and clinical practice. Br J Cancer 62:705-707

44. Zhang F, Xue J, Shao J, Jia L (2012) Compilation of 222 drugs' plasma protein binding data and guidance for study designs. Drug Discov Today 17:475-485 
45. Hardman JG, Limbird LE, Gilman AG (2001) Goodman \& Gilman's the pharmacological basis of therapeutics, 10th edn. McGraw-Hill, New York

46. Li B, Stribley JA, Ticu A, Xie W, Schopfer LM, Hammond P, Brimijoin S, Hinrichs SH, Lockridge O (2000) Abundant tissue butyrylcholinesterase and its possible function in the acetylcholinesterase knockout mouse. J Neurochem 75:1320-1331

47. Eng H, Niosi M, McDonald TS, Wolford A, Chen Y, Simila ST, Bauman JN, Warmus J, Kalgutkar AS (2010) Utility of the carboxylesterase inhibitor bis-para-nitrophenylphosphate (BNPP) in the plasma unbound fraction determination for a hydrolytically unstable amide derivative and agonist of the TGR5 receptor. Xenobiotica 40:369-380

48. Hatfield MJ, Potter PM (2011) Carboxylesterase inhibitors. Expert Opin Ther Pat 21:1159-1171
49. Morris BA, Robinson JD, Piall E, Aherne GW, Marks V (1975) Proceedings: development of a radioimmunoassay for morphine having minimal cross-reactivity with codeine. J Endocrinol 64: $6 \mathrm{P}-7 \mathrm{P}$

50. Findlay JW, Butz RF, Jones EC (1981) Relationships between immunogen structure and antisera specificity in the narcotic alkaloid series. Clin Chem 27:1524-1535

51. Beike J, Blaschke G, Mertz A, Kohler H, Brinkmann B (1999) A specific immunoassay for the determination of morphine and its glucuronides in human blood. Int J Legal Med 112:8-14

52. Usagawa T, Itoh Y, Hifumi E, Takeyasu A, Nakahara Y, Uda T (1993) Characterization of morphine-specific monoclonal antibodies showing minimal cross-reactivity with codeine. J Immunol Methods 157:143-148 